\title{
Environmental taxation in open economies: unilateralism or partial harmonization
}

\author{
Helmuth Cremer \\ University of Toulouse \\ (IDEI and GREMAQ) \\ Toulouse, France \\ Firouz Gahvari ${ }^{1}$ \\ Department of Economics \\ University of Illinois at Urbana-Champaign \\ Urbana, IL 61801, USA
}

This version, April 2005

${ }^{1}$ We thank Hormozd Gahvari for help in computations, and two anonymous referees for comments. 


\begin{abstract}
There are two reasons why countries might set weak environmental policies: transboundary pollution and concerns for competitiveness. This paper explores the full interactions between these two features within a unified general equilibrium framework. First, we show that competitive concerns change the structure of output taxes but not that of emission taxes. They lead to a lowering of output taxes, lower polluting good prices, an increase in emission taxes, adoption of less (or same) polluting technologies, increased aggregate emissions, and lower overall welfare levels. Secondly, we show that partially harmonizing commodity taxes, above their unrestricted Nash equilibrium value, can potentially hurt as well as improve the pollution technology, overall quality of the environment and welfare. The three attributes move positively together. On the other hand, harmonizing of emission taxes above their Nash equilibrium values appear to always lead to improvements in the environment and welfare via adoption of cleaner technologies.
\end{abstract}

JEL classification: $\mathrm{H} 21 ; \mathrm{H} 23 ; \mathrm{H} 73 ; \mathrm{H} 87 ; \mathrm{F} 15$

Keywords: Environmental taxation; global externality; tax competition; partial harmonization; polluting technology; environmental quality. 


\section{Introduction}

There are two international dimensions to environmental policies each raising a specific type of question. First, when pollution is worldwide (e.g., emissions of greenhouse gases like $\mathrm{CO}_{2}$ ) we are effectively dealing with a global and essentially pure public good, namely environmental quality. ${ }^{1}$ As measured for instance by the negative of the stock of $\mathrm{CO}_{2}$ in the atmosphere. Different countries contribute to this public good or, more precisely, they contribute towards its degradation through their emissions. As long as there is no supranational government, one has a framework which resembles that of the voluntary provision of public goods. The problem here is that individual countries do not have the right incentives to take the welfare of the other countries into consideration. Their cost/benefit calculus does not account for the full cost of the emissions imposed on the rest of the world. Consequently, one can expect (non-cooperative) national policies to lead to an "excessive" level of emissions. ${ }^{2}$ There is a vast literature on the inefficiency of non-cooperative provision of public goods; see, e.g., Cornes and Sandler (1996). In the context of transboundary emission, see Silva and Caplan (1997), and Caplan and Silva (1999). They examine the roles of federal and regional governments in combating pollution abstracting from tax competition.

The remedies that countries adopt to combat pollution introduce a second international dimension of their own. For example, when France unilaterally taxes domestic producers in order to entice them to cut their emissions, the price of domestic products will increase and consumers may turn to imported substitutes. This effect is of course neither intended nor in general positive for the French economy. In addition, it mitigates the environmental benefits of the policy since the non-taxed foreign producers can be expected to use dirtier technologies. This is indicative of the fact that unilateral environmental policies, regardless of the global or local character of pollution, are not immune to the phenomenon of "fiscal competition". When tax bases are mobile, the capacity of an individual country to levy taxes is reduced. This problem arises for most forms of taxation including for environmental levies. The fiscal competition aspect may then tempt an individual country to cut its environmental taxes in 
order to enhance the competitiveness of its economy as long as there is some degree of mobility of goods and/or factors. ${ }^{3}$ The tax competition have recently been surveyed by Cremer et al. (1996), Wilson (1999), Wellisch (2000) and Haufler (2001). For specific applications to environmental issues, see Oates (2001).

The two dimensions of international environmental policies have thus far been studied independently of one another - at least in a general equilibrium framework. ${ }^{4}$ There are papers which contain both strategic trade consideration and transboundary pollution; see, e.g., Conrad (1993) and Kennedy (1994). However, these papers are partial equilibrium in nature and model imperfectly competitive environments. As such, they do not explore the full interactions between tax competition and transboundary pollution. Each dimension alone suggests a reason for the environmental quality to be inefficiently low. One may then be tempted to argue that when the two elements are put together, they can only reinforce one another. However, the inefficiencies due to global nature of externalities and tax competition are not simply "additive". We present a model where the two problems are accounted for simultaneously, thus providing a single framework to study the complexities that are brought about by their interaction. In our model, emissions vary with the level of output and the polluting technology employed. This feature captures the different roles that output and emission taxes may play in financing government expenditures and combating emissions - the two instruments do not collapse to one. This provides an appropriate framework to study a number of questions regarding the design of environmental policies. Does economic integrations, and the potential for tax competition it induces, necessarily lead to a decline in environmental quality? And if so, how should one go about remedying this problem? Will there be a "targeting" of tax instruments with output taxes used for financing public goods and tax competition, and emission taxes solely for combating emissions? ${ }^{5}$ The targeting issue has been noted in the literature; see, e.g., Barrett (1994). Again, this has been studied within a partial equilibrium framework with restricted instruments. Of particular importance, in this respect, is the implications of a policy of "partial harmonization"; that is, harmonization in only one instrument. We shall examine, in particular, if harmonization of output taxes intended to avoid tax competition are "neutralized" by an adjustment 
of other taxes, like those that are directly imposed on emissions. ${ }^{6}$ Harmonization of a single instrument has been discussed in the literature. See Kanbur et al. (1995) and Ulph (2000) in the context of environmental policies and Keen (1989) and Kanbur and Keen (1993) for a general discussion. "Partial harmonization", as far as we know, was first discussed by Cremer and Gahvari (2000) in the context of tax evasion. See also the survey by Cremer and Pestieau (2002).

Certain aspects of the questions we are raising, have been studied in the literature. There is a huge literature on environmental dumping which compares cooperative and non-cooperative outcomes under trade; see Ulph (1997) for a survey. However, as a rule, this literature does not distinguish between emission and output taxes, ignores the question of the public good provision, and is cast in terms of competition between imperfectly competitive firms. In yet another approach, Antweiler et al. (2001) do distinguish between scale of output and the intensity of polluting technologies in determining emissions, but their concern is not tax competition and public good provision. ${ }^{7}$ There are numerous other trade models. Copeland and Taylor (1995), for example, motivate trade through income differences and show that trade worsens the environment by making rich countries specialize in production of clean goods and poor countries (with less stringent regulations) in dirty goods. They generalize their setup in Antweiler et al. (2001) by including factor abundance in determining trade. There are also papers that study the impact of trade on environmental resources; see, e.g., Chichilinisky (1994) and Karp et al. (2001) who build models of North-South trade and motivate trade through differences in property rights.

We consider a simple model of commodity tax competition. There are two identical countries whose inhabitants consume three goods: one publicly-provided locally and two privately-provided goods. The publicly-provided good is nonpolluting. One of the privately-provided good is the numeraire good which is also nonpolluting. The other privately-provided good is polluting. Every consumer has an endowment of the numeraire good, some of which he consumes, spending the rest to purchase the polluting good and pay taxes. Production technologies are identical in both countries. The publicly-provided good is produced at a constant average and marginal cost. 
Pollution $\left(\mathrm{CO}_{2}, \mathrm{SO}_{2}\right.$, etc. $)$ is global and a by-product of production. The polluting good may be produced in different ways. Each procedure entails a different resource cost and a different emission level. Emissions are beneficial in that a higher level of emission reduces the private (per unit) production costs of polluting goods. That is, the production costs of polluting goods are inversely related to their emissions. This is to capture the fact that technologies which cut emissions are more expensive to employ. Firms producing the polluting good operate in a competitive environment. The good is produced by an industry that is comprised of a fixed but sufficiently large number of identical firms. It is produced, for a given unit cost of production, by a linear technology subject to constant returns to scale. ${ }^{8}$ Firms also choose the environmental technologies with a view to maximize profits. This treatment differs from that of the literature on strategic environmental policies and trade with imperfect competition where the technology choices (e.g. through $\mathrm{R} \& \mathrm{D}$ ) are made strategically by firms. The latter approach adds additional features which are not treated here because of the competitive assumptions.

Each country provides the publicly-provided good to its own residents only. The polluting good is produced and consumed in both countries. Prior to economic integration, there is no trade between the two countries. Upon integration, residents of each country will be able to purchase the polluting good from the foreign as well as the home country. While the physical characteristics of the home- and foreign-produced goods are identical, consumers have a preference for purchasing the home-produced goods. We model this by assuming that consumers experience a certain disutility when they consume one unit of the foreign-produced good. The extent of the disutility differs across consumers. Individuals have otherwise identical quasi-linear preferences.

There are two (distortionary) tax instruments: commodity and emission taxes. These are "origin-based". Thus, each country levies a certain tax on each unit of the (polluting) consumption good that its firms produce and sell regardless of where the purchasers come from. Second, to combat pollution, the country imposes another tax per unit of emissions on (home) firms.

Within this framework, we characterize second-best commodity and emission tax 
rates. Next, we characterize the equilibrium values of commodity and emission taxes in closed and open economies. We show that the formula for the emission tax remains the same in open as in closed economies. On the other hand, the equilibrium value of the commodity tax changes and includes a negative term due to tax competition. The targeting principle applies; emission taxes are used only for the purpose of combating emissions and commodity taxes for tax competition. ${ }^{9}$ See Cremer and Gahvari (2001) for a thorough discussion of the properties of output taxes versus emission taxes in the context of a closed economy. The intuition for this result must be seen in the availability of output taxes for tax competition. As far as competitiveness in terms of prices is concerned, whatever the government of any particular country can do via emission taxes, it can also do via output taxes. However, the latter tax does not affect production decisions, but the former does. There is thus no reason for the government to want to use emission taxes and distort its production decisions. We show that lower prices lead to increased aggregate emissions, but that the firms will adopt less (or same) polluting technologies as the emission tax increases (or remains the same). Overall welfare declines. Finally, we show that partially harmonizing commodity taxes, above their unrestricted Nash equilibrium value, can potentially hurt as well as improve the pollution technology, overall quality of the environment and welfare. The three attributes move positively together. On the other hand, harmonizing of emission taxes above their Nash equilibrium values appear to always lead to improvements in the environment and welfare via adoption of cleaner technologies.

\section{The model}

Consider two identical countries, $A$ and $B$, whose inhabitants consume three goods: one publicly-provided (locally) and two privately-provided goods. The publicly-provided good, $G$, is nonpolluting. One of the privately-provided good is the numeraire good which is also nonpolluting. The other privately-provided good, $x$, is polluting. Every consumer has an endowment of $m$ units of the numeraire good, some of which he consumes, spending the rest to purchase the polluting good and pay his taxes. Production technologies are identical in both countries. The publicly-provided good is produced at 
a constant average and marginal cost which we can normalize at one.

Pollution is global and a by-product of production. The polluting good may be produced in different ways. Each procedure entails a different resource cost and a different emission level. ${ }^{10}$ This models situations where a polluting good may be produced through different production techniques, or using different polluting inputs where each particular input entails a different emission level. Different abatement techniques also imply that a unit of polluting good is associated with different emission levels. Specifically, assume that the resource cost of producing one unit of output $C\left(e_{i}\right)$, where $e_{i}$ $(i=A, B)$ denotes emission per unit of output in country $i$, is a continuously differentiable, decreasing and convex function of $e_{i} \cdot{ }^{11}$ More precisely the assumption is that $C^{\prime}()<$.0 for all $e_{i}(i=A, B)$ up to some limit $\bar{e}$, and that $C^{\prime}(\bar{e})=0$. Firms producing the polluting good operate in a competitive environment. The good is produced by an industry that is comprised of a fixed but sufficiently large number of identical firms. It is produced, for a given $C\left(e_{i}\right)$, also by a linear technology subject to constant returns to scale.

Each country provides the publicly-provided good to its own residents only. The polluting good is produced and consumed in both countries. Prior to economic integration, there is no trade between the two countries. Upon integration, citizens of each country will be able to purchase the polluting good from the foreign as well as the home country. While the physical characteristics of the home- and foreign-produced goods are identical, consumers have a preference for purchasing the home-produced goods. Let $\theta$ denote the inhabitants of $A$ and $B$, with $|\theta|$ determining $\theta$ 's disutility when consuming one unit of the foreign-produced good. Assume that $\theta$ is uniformly distributed over $[-1,1]$, with a negative $\theta$ indicating a resident of $B$ and a positive $\theta$ a resident of $A$. Normalize the population size in each country at one.

Consumers have quasi-linear preferences. Denote the utility level of a person in $j=$ $A, B$ who purchases the polluting good produced in $i=A, B$ by $u_{i}^{j}$ and his consumption of the polluting good by $x_{i}^{j}$. All consumers who buy from $i$, regardless of their country of origin, face the same consumer price for $x \cdot{ }^{12}$ All taxes are origin-based. Denote this price by $p_{i}$, the level of publicly-provided good in country $i$ by $G_{i}$, and the global emission 
level by $E$. We have:

$$
\left\{\begin{array}{l}
u_{j}^{j}=m-p_{j} x_{j}^{j}+h\left(x_{j}^{j}\right)+\phi\left(G_{j}\right)-\varphi(E), \\
u_{i}^{j}=m-p_{i} x_{i}^{j}+h\left(x_{i}^{j}\right)-\delta|\theta| x_{i}^{j}+\phi\left(G_{j}\right)-\varphi(E), \quad \text { with } j \neq i,
\end{array}\right.
$$

where $\delta>0$ is a "dislike index". Note that as $\delta$ becomes sufficiently "large", one never purchases the foreign-produced good regardless of the price. ${ }^{13}$ If $\delta=0$, individuals become identical in all respects. Under this circumstance, any deviation in price implies that no one will purchase from the state which has a higher price. Observe also that our approach is similar in structure to a model with cross-border shopping; see, e.g., Kanbur and Keen (1993). The disutility from consumption of foreign-produced goods here plays the same role as transportation cost, with different individuals facing different transportation costs reflecting their distance from the "border". We will also assume that $h($.$) and \phi($.$) are continuously differentiable, increasing and (strictly) concave functions$ of their argument while $\varphi($.$) is continuously differentiable, increasing and convex; that$ is, $h^{\prime}()>0,. h^{\prime \prime}()<0,. \phi^{\prime}()>0,. \phi^{\prime \prime}() \leq$.0 and $\varphi^{\prime}()>0,. \varphi^{\prime \prime}() \geq$.0 .

When a resident of country $j$ buys the home-produced good, his net cost of purchasing one unit of the good is simply its consumer price, $p_{j}$. On the other hand, when he buys the foreign-produced good, he incurs, per unit, a net (utility) cost of $p_{i}+\delta|\theta|$. In either case, the number of units the consumer buys corresponds to that which maximizes his utility. Thus assuming that $m$ is sufficiently large so that the consumer chooses to buy $x$,

$$
\left\{\begin{array}{l}
h^{\prime}\left(x_{j}^{j}\right)=p_{j}, \\
h^{\prime}\left(x_{i}^{j}\right)=p_{i}+\delta|\theta|, \quad \text { with } j \neq i .
\end{array}\right.
$$

Inverting these functions, one can write the demand for the polluting good as: $x_{j}^{j}=x\left(p_{j}\right)$ and $x_{i}^{j}=x\left(p_{i}+\delta|\theta|\right)$. Substituting in Equation 1 then yields $u_{j}^{j}=u\left(p_{j}, G_{j}, E\right)$ and $u_{i}^{j}=u\left(p_{i}+\delta|\theta|, G_{j}, E\right)$.

Denote the "marginal" consumer, i.e. the person who is just indifferent between buying home- or foreign-produced goods, by $\tilde{\theta}$. If the marginal consumer is a resident of $A(\tilde{\theta}>0), u\left(p_{A}, G_{A}, E\right)=u\left(p_{B}+\delta \tilde{\theta}, G_{A}, E\right)$. Similarly, if $\tilde{\theta}$ is a resident of $B(\tilde{\theta}<0)$, $u\left(p_{B}, G_{B}, E\right)=u\left(p_{A}-\delta \tilde{\theta}, G_{B}, E\right)$. It follows that, regardless of which country sells the 
good at a higher price,

$$
\tilde{\theta}=\frac{p_{A}-p_{B}}{\delta} .
$$

It then also follows that all individuals to the left of $\tilde{\theta}$ buy the good from country $B$, and all the individuals to the right of $\tilde{\theta}$ buy the good from country $A$.

\subsection{Tax instruments and government expenditures}

The properties of the equilibrium depend on what tax instruments are feasible. Assume that each country has two (distortionary) tax instruments: commodity and emission taxes. These are "origin-based". Thus, country $i(i=A, B)$ levies a tax of $\tau_{i}$ on each unit of the (polluting) consumption good that its firms produce and sell (regardless of where the purchasers come from). Second, to combat pollution, the country imposes a tax of $t_{i}$ per unit of emissions on (home) firms. ${ }^{14}$ We rule out lump-sum taxes. This is in line with the literature on tax competition. However, unlike that literature, allowing for lump-sum taxation here does not make tax competition disappear. This special case is studied in Cremer and Gahvari (2003). In the context of our model, ruling out lump-sum taxes implies ruling out taxation of the numeraire good. Alternatively, we can allow for a tax on $m$ provided that its value is fixed.

A representative firm in country $i$, regardless of where its purchasers come from, will have to sell its output at the domestic price of $p_{i}$ and pay domestic taxes $\tau_{i}$ and $t_{i}$. Moreover, given the constant returns to scale assumption, the firm's profit maximization problem is simply one of maximizing profits per unit of output. That is, the firm chooses $e_{i}$ to maximize

$$
p_{i}-C\left(e_{i}\right)-t_{i} e_{i}-\tau_{i} .
$$

This yields, for $i=A, B$,

$$
-C^{\prime}\left(e_{i}\right)=t_{i}
$$

where the second-order condition $C^{\prime \prime}\left(e_{i}\right)>0$ is satisfied from the convexity of $C($.$) .$ Moreover, the zero-profit condition implies that

$$
p_{i}=C\left(e_{i}\right)-C^{\prime}\left(e_{i}\right) e_{i}+\tau_{i} .
$$


Assume the governments of $A$ and $B$ undertake no other expenditures or transfers except for $G$, which is produced at a fixed unit cost normalized at one. With $p_{i}-C\left(e_{i}\right)=$ $t_{i} e_{i}+\tau_{i}(i=A, B)$, one can easily show that ${ }^{15}$ If $m$ is taxed at some fixed rate $\bar{m}$, one must add this to the right-hand side formulas. It is plain that this will have no impact on our formulation as long as the desired expenditure levels on $G$ exceed $\bar{m}$.

$$
\begin{gathered}
G_{A}\left(p_{A}, e_{A} ; p_{B}\right)= \begin{cases}{\left[p_{A}-C\left(e_{A}\right)\right](1-\tilde{\theta}) x\left(p_{A}\right)} & \text { if } p_{A} \geq p_{B}, \\
{\left[p_{A}-C\left(e_{A}\right)\right]\left[x\left(p_{A}\right)+\int_{\tilde{\theta}}^{0} x\left(p_{A}-\delta \theta\right) d \theta\right]} & \text { if } p_{A}<p_{B} .\end{cases} \\
G_{B}\left(p_{B}, e_{B} ; p_{A}\right)= \begin{cases}{\left[p_{B}-C\left(e_{B}\right)\right]\left[x\left(p_{B}\right)+\int_{0}^{\tilde{\theta}} x\left(p_{B}+\delta \theta\right) d \theta\right]} & \text { if } p_{A} \geq p_{B}, \\
{\left[p_{B}-C\left(e_{B}\right)\right](1+\tilde{\theta}) x\left(p_{B}\right)} & \text { if } p_{A}<p_{B} .\end{cases}
\end{gathered}
$$

In the same way, that total pollution, $E$, is related to each country's pollution according to

$$
E\left(p_{A}, p_{B}, e_{A}, e_{B}\right)= \begin{cases}e_{B}\left[x\left(p_{B}\right)+\int_{0}^{\tilde{\theta}} x\left(p_{B}+\delta \theta\right) d \theta\right]+e_{A}(1-\tilde{\theta}) x\left(p_{A}\right) & \text { if } p_{A} \geq p_{B} \\ e_{B}(1+\tilde{\theta}) x\left(p_{B}\right)+e_{A}\left[\int_{\tilde{\theta}}^{0} x\left(p_{A}-\delta \theta\right) d \theta+x\left(p_{A}\right)\right] & \text { if } p_{A}<p_{B}\end{cases}
$$

Note that at $p_{A}=p_{B}, \tilde{\theta}=0$ so that $G_{A}, G_{B}$ and $E$ are continuous at this point. The following Lemma, proved in the Appendix, shows that these functions are in fact differentiable at $p_{A}=p_{B}$.

Lemma 1 The functions $G_{A}\left(p_{A}, e_{A} ; p_{B}\right)$, given by Equation $6, G_{B}\left(p_{B}, e_{B} ; p_{A}\right)$, given by Equation 7, and $E\left(p_{A}, p_{B}, e_{A}, e_{B}\right)$, given by Equation 8, are continuously differentiable at $p_{A}=p_{B}$.

\subsection{Welfare}

It is natural, given our setup, to measure the welfare of each country on a utilitarian basis. Denote this utilitarian measure for country $i$ by $W_{i},(i=A, B)$. Define

$$
S(p) \equiv h(x(p))-p x(p),
$$


where $S(p)$ is the consumer surplus enjoyed by a person who buys $x(p)$ at the net price of $p$. Next, define

$$
\begin{aligned}
U_{i}\left(p_{i}, G_{i}, E\right) & \equiv \int_{0}^{1}\left[m-p_{i} x\left(p_{i}\right)+h\left(x\left(p_{i}\right)\right)+\phi\left(G_{i}\right)-\varphi(E)\right] d \theta \\
& =m+S\left(p_{i}\right)+\phi\left(G_{i}\right)-\varphi(E), \quad i=A, B .
\end{aligned}
$$

We prove in the Appendix that

Lemma 2 (i) We have:

$$
\begin{aligned}
& W_{A}= \begin{cases}U_{A}-\tilde{\theta} S\left(p_{A}\right)+\int_{0}^{\tilde{\theta}} S\left(p_{B}+\delta \theta\right) d \theta, & \text { if } p_{A} \geq p_{B}, \\
U_{A} & \text { if } p_{A}<p_{B} .\end{cases} \\
& W_{B}= \begin{cases}U_{B} & \text { if } p_{A} \geq p_{B}, \\
U_{B}+\tilde{\theta} S\left(p_{B}\right)+\int_{\tilde{\theta}}^{0} S\left(p_{A}-\delta \theta\right) d \theta, & \text { if } p_{A}<p_{B} .\end{cases}
\end{aligned}
$$

where $G_{i}$ and $E$ are given by Equations $6-7$ and 8.

(ii) $W_{A}\left(p_{A}, G_{A}, E ; p_{B}\right)$ and $W_{B}\left(p_{B}, G_{B}, E ; p_{A}\right)$ are continuously differentiable at $p_{A}=p_{B}$.

Note that the middle expression in the right-hand side of Equation 11 [when $p_{A} \geq p_{B}$ ] measures the consumer surplus that country $A$ does not get when some of its residents do not buy the home-produced good (at $p_{A}$ ). The last expression in the right-hand side, on the other hand, indicates the surplus attained by buying from $B$. It is plain that the last expression dominates the second so that the net change in consumer surplus is positive. ${ }^{16}$ These are the people with a $\theta \in[0, \tilde{\theta})$ for whom the net cost of buying one unit of the good from $B$ is $p_{B}+\delta \theta<p_{A}$. The same interpretation applies to Equation 12 and residents of $B$.

\subsection{Optimal benchmark}

Denote the welfare of each country at a symmetric allocation by $W_{i}^{S}, i=A, B$. Using Equation 10, one can write this as

$$
W_{i}^{S}\left(p_{i}, G_{i}, E\right)=m+S\left(p_{i}\right)+\phi\left(G_{i}\right)-\varphi(E) .
$$


Similarly, from Equations 6-7, $i$ 's budget constraint at a symmetric allocation is

$$
G_{i}=\left[p_{i}-C\left(e_{i}\right)\right] x\left(p_{i}\right)
$$

Assume that the two countries cooperate fully in their fiscal policies. That is, they do not engage in tax competition and set their emission taxes while taking the welfare of the citizen of both countries into account. Optimal symmetric allocations are found through maximization of $W_{i}^{S}$ subject to Equation 14 and

$$
E=2 e_{i} x\left(p_{i}\right) .
$$

The fiscal instruments in this optimization are, as observed earlier, $\tau_{i}$ and $t_{i} \cdot{ }^{17}$ Despite the "full cooperation" between the countries, the absence of lump-sum taxes implies that the optimal benchmark is second best. We prove in the Appendix that:

Proposition 1 Assume that countries set their environmental policies cooperatively. Denote the absolute value of the elasticity of demand for the polluting good in country $i, i=A, B$, by $\varepsilon_{i} \equiv-x^{\prime}\left(p_{i}\right) p_{i} / x\left(p_{i}\right)$. The optimal symmetric allocations, and the supporting prices and tax instruments, are characterized by Equations 2, 4, 5, 14, 15, and

$$
\begin{aligned}
\frac{\tau_{i}}{p_{i}} & =\frac{\phi^{\prime}\left(G_{i}\right)-1}{\phi^{\prime}\left(G_{i}\right) \varepsilon_{i}}, \\
-C^{\prime}\left(e_{i}\right) & =\frac{2 \varphi^{\prime}(E)}{\phi^{\prime}\left(G_{i}\right)} .
\end{aligned}
$$

Observe that Equation 16 reflects the well-known "elasticity rule" of optimal commodity taxes: The higher is $\varepsilon$, the smaller will be the required tax (assuming that $\left.\tau_{i}>0\right)$. Observe also that $\phi^{\prime}\left(G_{i}\right)$ is equal to the marginal cost of public funds (MCPF) in country $i$. As long as MCPF $>1, \phi^{\prime}\left(G_{i}\right)>1$ and $\tau_{i}>0$.

\section{Closed borders}

This section examines the properties of the equilibrium if the borders are closed (assuming that the government chooses the values of its fiscal instruments optimally). When there is no trade, everyone buys the home-produced good. The government's budget 
constraint in each country will thus be represented by Equation 14. Turning to aggregate emissions, setting $\tilde{\theta}$ in Equation 8 equal to zero yields

$$
E=e_{A} x\left(p_{A}\right)+e_{B} x\left(p_{B}\right) .
$$

Assume that the governments choose the values of their fiscal instruments (which determine their emission levels) simultaneously and non-cooperatively. A government's objective function is the welfare of its own residents. Consequently, it does not account for the impact of domestic emission on residents of foreign countries. This is in contrast to the "optimal benchmark" problem, where we assumed that each country takes the damage its emissions impose on the other country fully into account. Solving the "best-reply" functions for the two countries, assuming a symmetric Nash-equilibrium, leads to:

Proposition 2 The symmetric equilibrium allocations, and the supporting prices and taxes, in a closed economy are characterized (for $i=A, B$ ) by Equations 2, 4, 5, 14, 18 , and

$$
\begin{aligned}
\frac{\tau_{i}}{p_{i}} & =\frac{\phi^{\prime}\left(G_{i}\right)-1}{\phi^{\prime}\left(G_{i}\right) \varepsilon_{i}}, \\
-C^{\prime}\left(e_{i}\right) & =\frac{\varphi^{\prime}(E)}{\phi^{\prime}\left(G_{i}\right)} .
\end{aligned}
$$

Condition 19 is identical to condition 16 that characterized the second-best determination of $\tau_{i}$. This should not be surprising. With closed borders, there is no tax competition between the countries. Hence the optimal tax rule for setting $\tau_{i}$ remains unaffected. On the other hand, the rule for setting emission taxes now differs from the optimal benchmark case. Condition $-C^{\prime}\left(e_{i}\right)=\varphi^{\prime}(E) / \phi^{\prime}\left(G_{i}\right)$ in Equation 20 replaces condition $-C^{\prime}\left(e_{i}\right)=2 \varphi^{\prime}(E) / \phi^{\prime}\left(G_{i}\right)$ of the second-best. Thus, the environmental tax is set at one half the full marginal social damage of emissions. This reflects our earlier observation that each country, when determining its emissions policy, considers the damage to its own citizens only. Note that the $1 / 2$ factor corresponds to the relative size of the country to total global population. Apart from this factor, the Pigouvian formula remains unaffected. 


\section{Open borders}

With opening of the borders, the citizens of one country may find it advantageous to buy from the other country. Whether a particular individual would do that or not, depends on his distaste for the foreign-produced goods as explained in Section 2. This possibility has an important implication for a country's potential public revenues. When the borders are closed, the "tax base" (number of taxpayers) is the population size and is thus fixed. When borders open, the tax base becomes endogenous varying with the size of the price differentials between the two countries. The government of each country will then be able to affect it by the choice of its tax rates. This introduces an additional dimension to the strategic interaction between the countries. As in the previous Section, and following the tax competition literature, we assume that the countries choose their tax rates non-cooperatively and simultaneously.

Each country chooses its tax rates $t_{i}$ and $\tau_{i}$ to maximize its social welfare function while treating the values of the other country's tax instruments as given. This yields the best-reply functions of each country (to the other country's choice of values for its tax instruments). One can then determine the properties of the symmetric equilibrium of the Nash game in tax instruments through solving these best-reply function. We have the following result which we prove in the Appendix. ${ }^{18}$ If individuals have no preference for home-produced goods, i.e. if $\delta=0$, each state will be able to take over the production of $x$ in its entirety by selling at a price just below the other state's price. Under this circumstance, the price is pushed all the way down to the marginal cost so that $p_{i}-C\left(e_{i}\right)=\tau_{i}-C^{\prime}\left(e_{i}\right) e_{i}=0$. Consequently, in the absence of other taxes, $G_{i}=0$.

Observe also that by substituting for $G_{i}$ from 14 in 21 , one can rewrite it as

$$
\frac{\tau_{i}}{p_{i}}=\frac{\phi^{\prime}\left(G_{i}\right)-1}{\phi^{\prime}\left(G_{i}\right) \varepsilon_{i}}-\frac{p_{i}-C\left(e_{i}\right)}{\delta \varepsilon_{i}} .
$$

Next, substituting for $\tau_{i}$ from this equation and for $t_{i}$ from 22 in $p_{i}=C\left(e_{i}\right)+t_{i} e_{i}+\tau_{i}$ yields, after a bit of algebraic manipulation,

$$
p_{i}-C\left(e_{i}\right)=\frac{\delta}{p_{i}+\delta \varepsilon_{i}} \frac{\varphi^{\prime}(E) e_{i} \varepsilon_{i}+p_{i}\left[\phi^{\prime}\left(G_{i}\right)-1\right]}{\phi^{\prime}\left(G_{i}\right)} .
$$

It follows from this equation that as $\delta \rightarrow 0, p_{i} \rightarrow C\left(e_{i}\right)$. 
Proposition 3 The symmetric open-economy equilibrium allocations, and the supporting prices and taxes, in an open economy are characterized (for $i=A, B$ ) by Equations 2, 4, 5, 14, 18, and

$$
\begin{aligned}
\frac{\tau_{i}}{p_{i}} & =\frac{\phi^{\prime}\left(G_{i}\right)-1}{\phi^{\prime}\left(G_{i}\right) \varepsilon_{i}}-\frac{G_{i}}{\delta \varepsilon_{i} x\left(p_{i}\right)}, \\
-C^{\prime}\left(e_{i}\right) & =\frac{\varphi^{\prime}(E)}{\phi^{\prime}\left(G_{i}\right)}
\end{aligned}
$$

where $\varepsilon_{i}$ denotes the symmetric equilibrium absolute value of the elasticity of demand for $x_{i}$.

Comparisons of Equations 21-22 with their closed-economy counterparts Equations 19-20 reveal the effects of tax competition. First, opening the borders changes the closed-economy rule for setting the optimal commodity tax rate on $x_{i}$ by $-G_{i} / \delta \varepsilon_{i} x\left(p_{i}\right)$. The intuition is due to the familiar "fiscal externality" arguments. As with models of tax competition in the absence of emissions, an increase in the commodity tax of the home country affects the welfare of the foreign country's residents through a a taxbase effect (positive), and a private consumption externality (a negative externality on foreign country residents who buy from the home country). ${ }^{19}$ See, among others, Mintz and Tulkens (1986). Lockwood (2001) has termed these externalities "consumer price spillovers". The last term in Equation 21 reflects the combined effect of these two sources of externalities. ${ }^{20}$ Observe that the global nature of emissions here introduces a third source of externality: The increase in the home-country's tax increases the price of the polluting good and reduces its consumption. Consequently, aggregate emissions fall, benefiting the foreign country residents as well. However, this is not a fiscal externality and is also present when the economy is closed.

Second, the rule for setting the optimal emission tax remains unaffected (as compared to the closed economy case); see Equations 20 and 22: The marginal social damage of emissions (to a resident of $i$ ) is evaluated by its government by the same Pigouvian rule whether the economy is closed or open. This suggests a targeting of tax instruments: use commodity taxes for tax competition and reserve emission taxes for the purpose of combating emissions only. The intuition for this result must be sought in the 
availability of $\tau_{i}$ for tax competition. Whereas changing $\tau_{i}$ does not affect production decisions, changing $t_{i}$ is distortionary in this regard. Now, with $p_{i}=C\left(e_{i}\right)+t_{i} e_{i}+\tau_{i}$, whatever the government of $i$ wishes to do through $t_{i}$, it can also do via $\tau_{i}$. There is thus no reason for $i$ to want to use $t_{i}$ and distort its production decisions.

The next interesting question relates to the equilibrium levels of emissions and welfare under open borders. Specifically, one wants to know how they compare with their corresponding values if the borders are closed. The main import of Propositions 2-3 is that economic integration leads to competition in output taxes. This tends to bring about lower prices for polluting goods and boost their consumption and, with it, aggregate emissions. One would then also expect to see lower overall welfare levels. It is nevertheless rather difficult to establish these points by simply comparing the tax rules. The concomitant change in $G_{i}$, due to the change in the output tax, affects the marginal utility of public goods and through it the emission tax. The change in emission tax then affects the choice of emission technology and alters aggregate emissions. Sorting out this complex inter-relationship requires further simplification in the specification of our model. We make two assumptions: the marginal utility of public good and the elasticity of demand for the polluting good are constant. ${ }^{21}$ The assumption of a constant $\phi^{\prime}(G)$ is not unreasonable, if one remembers that variations in emission taxes are unlikely to change the MCPF by much (although such variations will change the environmental tax revenues).

Set $\phi^{\prime}\left(G_{i}\right)=\phi^{\prime}>1\left[\right.$ recall that $\phi^{\prime}\left(G_{i}\right)$ is the MCPF in $i$, and assume $\varepsilon_{i}=\varepsilon$ is constant. It then immediately follows from Equations 19 and 21 that $\tau_{i} / p_{i}$ is equal to $\left(1-1 / \phi^{\prime}\right) \varepsilon$, when the economy is closed, and equal to $\left[1-1 / \phi^{\prime}-e_{i} \varphi^{\prime}(E) / \delta\right] /\left(\varepsilon+p_{i} / \delta\right)$, when the borders are open. Consequently, assuming a constant elasticity of demand, $\tau_{i} / p_{i}$ decreases when the economy opens up. Indeed, it is quite possible for $\tau_{i} / p_{i}$ (which is positive under closed-borders) to become negative with open borders. ${ }^{22}$ This will be the case if $e_{i} \varphi^{\prime}(E)>\delta\left(1-1 / \phi^{\prime}\right)$. The latter condition will be satisfied if $\phi^{\prime}$ is "close" to one, i.e. if MCPF is "low", or if $\delta$ is "low".

It is not easy, however, to see what happens to emission levels. To examine this issue, we use the property that as $\delta \rightarrow \infty$, the open-border solution converges to the 
closed-border solution. This is intuitively plain because when $\delta$ is "very high" everybody purchases the home-produced good. One can also demonstrate this property formally from the expressions that characterize the two equilibria (which are identical except for the expression for $\tau_{i}$ ). These are Equations 4, 14, 15 and 22. The $\tau_{i}$ itself, is given by Equation 19 in a closed economy and Equation 21 in an open economy. Now, observe that as the value of $\delta$ increases, the optimal choice of $\tau_{i}$ in the open economy converges to the optimal choice of $\tau_{i}$ in the closed economy so that the two equilibria converge.

To compare the values of the relevant variables under the two solutions, we study the comparative statics properties of the open-border solution as $\delta$ varies. We show in the Appendix that as $\delta$ increases, the open-economy equilibrium values of $t_{i}$ and $E$ decrease while the values of $\tau_{i}, p_{i}, e_{i}$ and $W_{i}^{S}$ increase. ${ }^{23}$ If $\varphi^{\prime \prime}(E)=0, e_{i}$ remains unaffected. This tells us that the open-economy values of $t_{i}$ and $E$ exceed, and those of $\tau_{i}, p_{i}, e_{i}$ and $W_{i}^{S}$ fall short of, their closed-equilibrium values. Intuitively, tax competition lowers $\tau_{i}$ and through it $p_{i}$. This increases each individual's consumption of polluting goods and, with it, aggregate emissions. As aggregate emissions increase, its marginal social damage increases. To combat this, the emission tax is raised. This induces the firms to switch to less-polluting technologies, thus mitigating the negative impact of increased consumption on aggregate emissions. This effect notwithstanding, the increased aggregate emissions lowers overall welfare.

We have:

Proposition 4 Assume the marginal utility for public goods, and the elasticity of demand for polluting goods, are constant. Then, economic integration leads to a lowering of output taxes, lower polluting good prices, an increase in emission taxes, adoption of less (or same) polluting technologies, increased aggregate emissions, and lower overall welfare levels. ${ }^{24}$ We have carried out numerous simulations assuming $\phi^{\prime}\left(G_{i}\right)$ is not constant. In all cases we find similar results. The only exception is that it is possible for the emission tax to decline so that technologies become more polluting. Indeed, one can show that when demand is perfectly inelastic, $t_{i}$ must decline and $e_{i}$ must increase. Nevertheless aggregate emissions always increase and overall welfare declines. 


\section{Commodity tax harmonization}

A commonplace result of the tax competition literature is that of the restoration of the first-best allocations through the coordination of fiscal policies particularly a "harmonized" tax policy. In the context of our model, restoring second best requires harmonization of both output and emission taxes. In practice, however, such a sweeping coordination is rather difficult to achieve. It is more likely that countries coordinate their policies on a piecemeal basis. In our setting, this can occur in two ways. One may harmonize commodity taxes and let emission taxes be determined independently. Alternatively, the countries may harmonize their emission taxes and then determine output taxes independently. What can we say about the outcome of either of these "restricted" competition? Will such "partial" harmonization policies help? In particular, one would like to know if it would have the intended impact on the environment and on welfare. Intuitively, the possible concern is that the neutralization of one variable of fiscal competition, may make competition in the other variable even fiercer and that this may give rise to perverse results. For instance, a harmonization of output taxes could result in a lowering of emission taxes and thus in a switch to more polluting technologies. In studying this question, and as previously, we model the strategic interaction between the countries using the Nash equilibrium concept. This section discusses harmonization of commodity taxes taking up the harmonization of emission taxes in the next section. We start by adopting the following terminology.

Definition 1 The countries are said to "harmonize" a policy instrument if they set its value at a common specified level.

Let the two countries harmonize their commodity tax rates at $\tau=\hat{\tau}$. Each country then chooses the value of its emission tax to maximize the welfare of its citizens. This is done à la Nash assuming that the optimizing country treats the value of the other country's emission tax as given. In this way, one derives each country's best-reply function (to the other country's choice of a value for its emission tax). ${ }^{25}$ The best-reply function for $i$ is given by equation A34 in the Appendix when $\tau_{i}$ is set at $\hat{\tau}$. Finally, solving the best-reply functions yield the Nash equilibrium value of the emission tax. 
It is easy to show that the Nash equilibrium value of $t_{i}$, conditional on $\tau=\hat{\tau}$, is the solution to ${ }^{26}$ That is, the solution to 23 in conjunction with equations $2,4,5,14$, and 18.

If $\delta=0$, tax competition pushes the price down to the point such that $p_{i}-C\left(e_{i}\right)=$ $\hat{\tau}-C^{\prime}\left(e_{i}\right) e_{i}=0$. Consequently, $e_{i}$ is determined according to $C^{\prime}\left(e_{i}\right) e_{i}=\hat{\tau}$. Observe that if $\hat{\tau}>0, e_{i}>\bar{e}$.

$$
\left[\frac{\phi^{\prime}\left(G_{i}\right)-1}{\phi^{\prime}\left(G_{i}\right) \varepsilon_{i}}-\frac{p_{i}-C\left(e_{i}\right)}{\delta \varepsilon_{i}}-\frac{\tau_{i}}{p_{i}}\right]+\left[\frac{e_{i}}{p_{i}}+\frac{1}{C^{\prime \prime}\left(e_{i}\right) e_{i} \varepsilon_{i}}\right]\left[C^{\prime}\left(e_{i}\right)+\frac{\varphi^{\prime}(E)}{\phi^{\prime}\left(G_{i}\right)}\right]=0 .
$$

Denote this solution by $t^{N}(\hat{\tau})$ and the corresponding solutions for $e, E, G, p$ by $e^{N}(\hat{\tau})$, $E^{N}(\hat{\tau}), G^{N}(\hat{\tau})$ and $p^{N}(\hat{\tau})$. Further denote all unrestricted Nash equilibrium values by the superscript $N\left(\tau^{N}, t^{N}, e^{N}, E^{N}, G^{N}\right.$ and $\left.p^{N}\right)$. It is clear that if one were to harmonize $\tau$ at its unrestricted Nash equilibrium value, $t$ and all the other variables will also take their Nash equilibrium values. Equation 23 bears this out: When $\tau$ is unrestricted, the first bracketed expression in the right-hand side of Equation 23 will be zero.

\subsection{Harmonization and the environment}

To study the effects of harmonization on the environment, we have to first determine how harmonization impacts $t^{N}(\hat{\tau})$. To this end, differentiate Equation 23 with respect to $\hat{\tau}$ and evaluate the resulting expression at $\left(t^{N}, \tau^{N}\right)$. To simplify the derivations, we assume that the elasticity of demand for the polluting good, marginal utility of public good and marginal social damage of emissions are constant. We have (see the Appendix)

$$
\frac{d t^{N}(\hat{\tau})}{d \hat{\tau}}=\frac{-1}{e+\frac{C^{\prime}(e) e+\delta}{C^{\prime \prime}(e) e[1+(1-\tau / p) \delta \varepsilon / p]}}
$$

where we have dropped the $i$ subscript for ease in notation. It is clear from Equation 24 that at "high" values of $\delta,{ }^{27} \mathrm{~A}$ sufficient condition is that $\delta>-C^{\prime}(e) e . d t^{N}(\hat{\tau}) / d \hat{\tau}$ is negative. Intuitively, under this circumstance, restricting the competition in $\tau$ induces the countries to compete in $t$ and to lower its equilibrium value. Under this circumstance, $e^{N}(\hat{\tau})$ exceeds its unrestricted Nash equilibrium value so that harmonizing $\tau$ at "just above" its Nash equilibrium value will have a detrimental effect on the choice of the polluting technology. However, a beneficial effect is also possible if $\delta$ is "low". ${ }^{28}$ This 
may appear counterintuitive as one expects the two countries to have an incentive to unilaterally lower their emission tax rate if they cannot compete in $\tau$. However, this does not necessarily imply that the constrained Nash-equilibrium level of $t$ decreases. That depends on where the two countries' new best-reply functions (in emission taxes) intersect. We have numerical examples for both possibilities.

Next, to determine what happens to aggregate emissions, differentiate $E=2 e x(p)$ with respect to $\hat{\tau}$. After a bit of algebraic manipulation, we get

$$
\frac{d E^{N}(\hat{\tau})}{d \hat{\tau}}=2 x(p)\left[\frac{\frac{1}{\delta \varepsilon}-\frac{C^{\prime}(e) e}{\delta p}-\frac{\tau}{p^{2}}}{\frac{1}{\delta \varepsilon}+\frac{1}{p}\left(1-\frac{\tau}{p}\right)}\right] \frac{d e^{N}(\hat{\tau})}{d \hat{\tau}} .
$$

Assuming MCPF is not too high so that $\phi^{\prime}(G)$ is "close" to one (or that $\delta$ is "low"), the bracketed expression in the right-hand side of Equation 25 is positive and $E$ always moves positively with $e .{ }^{29}$ Recall that under either of these assumptions, the unrestricted Nash equilibrium value of $\tau$ is negative. Specifically, from 21), $T^{N}<0$, if $p-C(e)>$ $\delta\left[1-1 / \phi^{\prime}(G)\right]$.

To get an idea of what we mean by "low," consider the following numbers: $\phi^{\prime}(G)=$ 1.3 and $\delta=p$. The assumption of $\phi^{\prime}(G)=1.3$ means a value of 1.3 for the MCPF which is clearly on the high side of the estimates for the MCPF in the US; see, e.g., Fullerton (1991). As to $\delta=p$, recall that net utility cost of consuming the foreignproduced good ranges from $p$ to $p+\delta$ to people living in the home country. Hence the average net price is $p+\delta / 2$. A value of $\delta=p$ thus implies that, on average, an otherwise identical foreign-produced good is considered to cost (in utility terms) $50 \%$ more than its monetary price. This then is also on the high side. Nevertheless these two values imply that as long as the consumer price of $x$ exceeds its production cost by $30 \%$ or higher, $T^{N}<0$. With a $\mathrm{MCPF}=1.1$, and $\delta=p / 2$ (a $25 \%$ cost premium for foreign goods), $T^{N}<0$ as long as the price-cost differential is $4.8 \%$ or higher.

\subsection{Harmonization and welfare}

The above discussion indicates that harmonizing $\tau_{i}$ at $\hat{\tau}>\tau^{N}$ may harm the environment. A related question is whether such a policy is welfare reducing. To answer this question, use Equation 13 to write a country's welfare, at a symmetric Nash equilibrium 
with $\tau=\hat{\tau}$, as

$$
W^{S}\left(t^{N}(\hat{\tau}), \hat{\tau}\right)=m+S\left(p^{N}(\hat{\tau})\right)+\phi\left(G^{N}(\hat{\tau})-\varphi\left(E^{N}(\hat{\tau})\right)\right.
$$

where we have dropped the $i$ subscript for ease in notation. Differentiate $W^{S}\left(t^{N}(\hat{\tau}), \hat{\tau}\right)$ totally with respect to $\hat{\tau}$ to get

$$
\frac{d W^{S}\left(t^{N}(\hat{\tau}), \hat{\tau}\right)}{d \hat{\tau}}=\frac{\partial W^{S}\left(t^{N}(\hat{\tau}), \hat{\tau}\right)}{\partial \hat{\tau}}+\frac{\partial W^{S}\left(t^{N}(\hat{\tau}), \hat{\tau}\right)}{\partial t^{N}(\hat{\tau})} \frac{d t^{N}(\hat{\tau})}{d \hat{\tau}} .
$$

In the Appendix, we derive the expressions for $\partial W^{S} / \partial \hat{\tau}$ and $\partial W^{S} / \partial t^{N}(\hat{\tau})$. It follows from these expressions and Equation 24 that at $\hat{\tau}=\tau^{N}$,

$$
\frac{d W^{S}\left(t^{N}(\hat{\tau}), \hat{\tau}\right)}{d \hat{\tau}}=-x(p)\left\{\frac{\varphi^{\prime}(E)\left[\frac{p-C(e)}{\delta^{2} \varepsilon}+\frac{\varphi^{\prime}(E) e}{\phi^{\prime} \delta p}-\frac{\hat{\tau}}{p^{2}}\right]-\frac{\phi^{\prime} \hat{\tau}}{\delta \varepsilon e}}{\frac{1}{\delta \varepsilon}+\frac{1}{p}\left(1-\frac{\hat{\tau}}{p}\right)}\right\} \frac{d e^{N}(\hat{\tau})}{d \hat{\tau}} .
$$

Again, assuming the MCPF is not too high (or $\delta$ is "low"), the bracketed expression in the right-hand side of Equation 28 is positive. Equation 28 then tells us that welfare always moves negatively with $e$ (and with $E$ since $e$ and $E$ move positively together).

The results of this section are summarized as:

Proposition 5 Assume that the elasticity of demand for polluting good, the marginal social damage of emissions and the marginal utility of public good are constant. If countries $A$ and $B$ harmonize their commodity tax rates at a rate "just above" its unrestricted symmetric Nash equilibrium value,

(i) Firms will adopt a more polluting technology, if $\delta$ is "high" and may adopt a less polluting technology if $\delta$ is "low".

(ii) Aggregate emissions move positively and overall welfare negatively with the intensity of the pollution technology, provided that the marginal cost of public funds is not "very high."

\section{Emission tax harmonization}

Instead of commodity taxes, let the two countries harmonize their emission taxes (at $t=\hat{t})$. Each country then chooses the value of its commodity tax to maximize the welfare of its citizens. As previously, we assume this is done à la Nash. It is easy to 
show that the Nash equilibrium value of $\tau_{i}$, conditional on $t=\hat{t}$, is the solution $\operatorname{to}^{30}$ Of course, one must solve 29 in conjunction with equations $(2,4,5,14$, and 18). Note also that the best-reply function for $i$ is given by equation A35 in the Appendix when $t_{i}$ is set at $\hat{t}$.

If $\delta=0$, tax competition pushes the price down to the point where $p_{i}-C(\hat{e})=$ $\tau+\hat{t} \hat{e}=0$. Consequently, $\tau=-\hat{t} \hat{e}$.

$$
\frac{\phi^{\prime}\left(G_{i}\right)-1}{\phi^{\prime}\left(G_{i}\right) \varepsilon_{i}}-\frac{p_{i}-C\left(e_{i}\right)}{\delta \varepsilon_{i}}-\frac{\tau_{i}}{p_{i}}+\frac{e_{i}}{p_{i}}\left[C^{\prime}\left(e_{i}\right)+\frac{\varphi^{\prime}(E)}{\phi^{\prime}\left(G_{i}\right)}\right]=0 .
$$

Denote this solution by $\tau^{N}(\hat{t})$ and the corresponding solutions for $e, E, G, p$ by $e^{N}(\hat{t})$, $E^{N}(\hat{t}), G^{N}(\hat{t})$ and $p^{N}(\hat{t})$. Note that when $t$ is unrestricted, the bracketed expression in the left-hand side of Equation 29 will be zero so that $\tau$ will also take its unrestricted Nash equilibrium value, $\tau^{N}$.

\subsection{Harmonization and the environment}

It is clear that fixing $t_{i}$ fixes $e_{i}$ and thus the emission technology. Thus if one were to harmonize the emission tax rate above its unrestricted Nash equilibrium value, the firms will adopt less polluting technologies. What is not clear, however, is the impact of this on $E$ and thus on the overall environmental quality. There is another factor here; namely what happens to the aggregate production of the polluting good. This in turn depends on $p$ and thus on the Nash equilibrium level of $\tau, \tau^{N}(\hat{t})$. To study these additional effects, we differentiate Equation 29 with respect to $\hat{t}$ and evaluate the resulting expression at $\left(t^{N}, \tau^{N}\right)$. To simplify the derivations, we continue to assume that the marginal utility of public good, the elasticity of demand for polluting good and the marginal social damage of emissions are constant. We have (see the Appendix)

$$
\frac{d \tau^{N}(\hat{t})}{d \hat{t}}=-e-\frac{C^{\prime}(e)}{C^{\prime \prime}(e)[1+(1-\tau / p) \delta \varepsilon / p]} .
$$

The sign of the above expression appears to be ambiguous. Nevertheless the value of $d \tau^{N}(\hat{t}) / d \hat{t}$ implies that $p^{N}(\hat{t})$ is increasing in $\hat{t}$ at $\hat{t}=t^{N}$. To see this, differentiate $p=C(e)-C^{\prime}(e) e+\tau$ with respect to $\hat{t}$ :

$$
\frac{d p}{d \hat{t}}=e+\frac{d \tau}{d \hat{t}}
$$


Substituting from Equation 30 in above yields

$$
\frac{d p^{N}(\hat{t})}{d \hat{t}}=-\frac{C^{\prime}(e)}{C^{\prime \prime}(e)[1+(1-\tau / p) \delta \varepsilon / p]},
$$

which is positive when evaluated at $\hat{t}=t^{N}$. This follows from the convexity of $C($.$) and$ the fact that $(1-\tau / p)>0$.

Armed with this result, one can easily determine the effect of harmonization on aggregate emissions. Differentiate $E=2 e x(p)$ with respect to $\hat{t}$. After a bit of algebraic manipulation, we get

$$
\frac{d E^{N}(\hat{t})}{d \hat{t}}=-2 x(p)\left[\frac{1}{C^{\prime \prime}(e)}+\frac{e \varepsilon}{p} \frac{d p^{N}(\hat{t})}{d \hat{t}}\right] .
$$

With $d p^{N}(\hat{t}) / d \hat{t}>0$, the bracketed expression in the right-hand side of Equation 32 will also be positive. Consequently, Equation 32 indicates that harmonizing $t$ at just above its unrestricted Nash equilibrium value, reduces aggregate emissions.

\subsection{Harmonization and welfare}

We have shown that harmonizing the emission tax rate reduces per unit as well as aggregate emissions. Consequently, one would expect that this form of partial harmonization will have a positive impact on overall welfare. We now show that this conjecture is indeed correct.

Use Equation 13 to write a country's welfare, at a symmetric Nash equilibrium with $t=\hat{t}$, as ${ }^{31}$ We have again dropped the $i$ subscript for ease in notation.

$$
W^{S}\left(\tau^{N}(\hat{t}), \hat{t}\right)=m+S\left(p^{N}(\hat{t})\right)+\phi\left(G^{N}(\hat{t})\right)-\varphi\left(E^{N}(\hat{t})\right)
$$

Differentiate $W^{S}\left(\tau^{N}(\hat{t}), \hat{t}\right)$ totally with respect to $\hat{t}$ to get

$$
\frac{d W^{S}\left(\tau^{N}(\hat{t}), \hat{t}\right)}{d \hat{t}}=\frac{\partial W^{S}\left(\tau^{N}(\hat{t}), \hat{t}\right)}{\partial \hat{t}}+\frac{\partial W^{S}\left(\tau^{N}(\hat{t}), \hat{t}\right)}{\partial \tau^{N}(\hat{t})} \frac{d \tau^{N}(\hat{t})}{d \hat{t}}
$$

Next, substitute the expressions for $\partial W^{S} / \partial \hat{\tau}$ and $\partial W^{S} / \partial t^{N}(\hat{\tau})$ (derived in the Appendix), and $d \tau^{N}(\hat{t}) / d \hat{t}$ from Equation 30, in Equation 34 and simplify. We have at $\hat{t}=t^{N}$,

$$
\frac{d W^{S}\left(\tau^{N}(\hat{t}), \hat{t}\right)}{d \hat{t}}=x(p) \varepsilon\left[\frac{p-C(e)}{\delta \varepsilon} \phi^{\prime}+\frac{\varphi^{\prime}(E) e}{p}\right] \frac{d p^{N}(\hat{t})}{d \hat{t}}+\frac{x(p) \varphi^{\prime}(E)}{C^{\prime \prime}(e)}>0 .
$$


The sign of Equation 35 follows from the fact that $d p^{N}(\hat{t}) / d \hat{t}>0$ and the convexity of $C($.$) .$

The results of this section are summarized as:

Proposition 6 Assume that the elasticity of demand for polluting good, the marginal social damage of emissions and the marginal utility of public good are constant. If countries $A$ and $B$ harmonize their emission tax rates at a rate "just above" its unrestricted symmetric Nash equilibrium value, the quality of the environment and overall level of welfare in both countries will improve.

\section{Conclusion}

This paper has studied the full interactions between transboundary pollution and concerns for competitiveness in setting environmental taxes within a unified general equilibrium framework. What has emerged quite clearly is that the inefficiencies due to global externalities and tax competition are not simply additive. Instead, there is a rich and complex interrelationship between them. The paper has shown that competitive concerns change the structure of output taxes but not that of emission taxes. The targeting principle applies; emission taxes are used only for the purpose of combating emissions and commodity taxes for tax competition. Intuitively, a country can achieve a competitive edge through reducing either its output or emission taxes. Now whereas the output tax is neutral with respect to production decisions, the emission tax is not. There is thus no reason for the government to want to use emission taxes and distort its production decisions.

Secondly, we studied the efficacy of partial tax harmonization policies and their impact on the environment and welfare. Here, we showed that partially harmonizing emission taxes (above their unrestricted Nash equilibrium value) encourages firms to adopt cleaner technologies, improves environmental quality and enhances welfare. The effects of commodity tax harmonization, on the other hand, can go either way. A policy of partially harmonizing commodity taxes, above their unrestricted Nash equilibrium value, may be helpful in that it may lead to the adoption of technologies that are less 
polluting, improve the overall quality of the environment, and enhance welfare. On the other hand, such a policy is also potentially damaging. It can induce firms to switch to more polluting technologies, hurt the overall environmental quality, and lower welfare. This suggests that countries will have to be very careful when they do not fully coordinate their policies. Whether or not a particular harmonization policy should be adopted depends on the specifics of the policy, the demand and cost functions, and how much the people care about the environment. Theory alone cannot settle this. 


\section{Appendix}

Derivation of Equations 6,7, 8: We have

$$
\begin{gathered}
G_{A}= \begin{cases}\int_{\tilde{\tilde{\theta}}}^{1}\left[p_{A}-C\left(e_{A}\right)\right] x_{A}^{A} d \theta & \text { if } p_{A} \geq p_{B}, \\
\int_{\tilde{\theta}}^{0}\left[p_{A}-C\left(e_{A}\right)\right] x_{A}^{B} d \theta+\int_{0}^{1}\left[p_{A}-C\left(e_{A}\right)\right] x_{A}^{A} d \theta & \text { if } p_{A}<p_{B},\end{cases} \\
G_{B}= \begin{cases}\int_{\overline{\tilde{\theta}} 1}^{0}\left[p_{B}-C\left(e_{B}\right)\right] x_{B}^{B} d \theta+\int_{0}^{\tilde{\theta}}\left[p_{B}-C\left(e_{B}\right)\right] x_{B}^{A} d \theta & \text { if } p_{A} \geq p_{B}, \\
\int_{-1}^{\sigma_{1}}\left[p_{B}-C\left(e_{B}\right)\right] x_{B}^{B} d \theta & \text { if } p_{A}<p_{B} .\end{cases}
\end{gathered}
$$

And

$$
E= \begin{cases}\int_{-1}^{0} e_{B} x_{B}^{B} d \theta+\int_{0}^{\tilde{\theta}} e_{B} x_{B}^{A} d \theta+\int_{\tilde{\theta}}^{1} e_{A} x_{A}^{A} d \theta & \text { if } p_{A} \geq p_{B} \\ \int_{-1}^{\tilde{\theta}} e_{B} x_{B}^{B} d \theta+\int_{\tilde{\theta}}^{0} e_{A} x_{A}^{B} d \theta+\int_{0}^{1} e_{A} x_{A}^{A} d \theta & \text { if } p_{A}<p_{B} .\end{cases}
$$

Simplifying yields Equations $6-7$ and 8 in the text.

Proof of Lemma 1: Partially differentiate Equations 6 and 8 with respect to $p_{A}$ and $e_{A}$, and Equations 7 and 8 with respect to $p_{B}$ and $e_{B}$. We have

$$
\begin{aligned}
& \frac{\partial G_{A}}{\partial p_{A}}=\left\{\begin{array}{l}
(1-\tilde{\theta}) x\left(p_{A}\right)-\frac{1}{\delta}\left[p_{A}-C\left(e_{A}\right)\right] x\left(p_{A}\right)+\left[p_{A}-C\left(e_{A}\right)\right](1-\tilde{\theta}) x^{\prime}\left(p_{A}\right) \\
x\left(p_{A}\right)+\int_{\tilde{\theta}}^{0} x\left(p_{A}-\delta \theta\right) d \theta+\left[p_{A}-C\left(e_{A}\right)\right]\left[x^{\prime}\left(p_{A}\right)-\frac{1}{\delta} x\left(p_{A}\right)\right]
\end{array}\right. \\
& \frac{\partial G_{B}}{\partial p_{B}}=\left\{\begin{array}{l}
x\left(p_{B}\right)+\int_{0}^{\tilde{\theta}} x\left(p_{B}+\delta \theta\right) d \theta+\left[p_{B}-C\left(e_{B}\right)\right]\left[x^{\prime}\left(p_{B}\right)-\frac{1}{\delta} x\left(p_{B}\right)\right] \\
(1+\tilde{\theta}) x\left(p_{B}\right)-\frac{1}{\delta}\left[p_{B}-C\left(e_{B}\right)\right] x\left(p_{B}\right)+\left[p_{B}-C\left(e_{B}\right)\right](1+\tilde{\theta}) x^{\prime}\left(p_{B}\right)
\end{array}\right. \\
& \frac{\partial E}{\partial p_{A}}= \begin{cases}\frac{1}{\delta} e_{B} x\left(p_{B}+\delta \tilde{\theta}\right)-\frac{1}{\delta} e_{A} x\left(p_{A}\right)+(1-\tilde{\theta}) e_{A} x^{\prime}\left(p_{A}\right) & \text { if } p_{A} \geq p_{B}, \\
\frac{1}{\delta} e_{B} x\left(p_{B}\right)+e_{A}\left[x^{\prime}\left(p_{A}\right)-\frac{1}{\delta} x\left(p_{A}\right)\right] & \text { if } p_{A}<p_{B} .\end{cases} \\
& \frac{\partial E}{\partial p_{B}}= \begin{cases}e_{B}\left[x^{\prime}\left(p_{B}\right)-\frac{1}{\delta} x\left(p_{B}\right)\right]+\frac{1}{\delta} e_{A} x\left(p_{A}\right) & \text { if } p_{A} \geq p_{B}, \\
-\frac{1}{\delta} e_{B} x\left(p_{B}\right)+(1+\tilde{\theta}) e_{B} x^{\prime}\left(p_{B}\right)+\frac{1}{\delta} e_{A} x\left(p_{A}-\delta \tilde{\theta}\right) & \text { if } p_{A}<p_{B} .\end{cases} \\
& \frac{\partial G_{A}}{\partial e_{A}}= \begin{cases}-C^{\prime}\left(e_{A}\right)(1-\tilde{\theta}) x\left(p_{A}\right) & \text { if } p_{A} \geq p_{B}, \\
-C^{\prime}\left(e_{A}\right)\left[x\left(p_{A}\right)+\int_{\tilde{\theta}}^{0} x\left(p_{A}-\delta \theta\right) d \theta\right] & \text { if } p_{A}<p_{B} .\end{cases} \\
& \frac{\partial G_{B}}{\partial e_{B}}= \begin{cases}-C^{\prime}\left(e_{B}\right)\left[x\left(p_{B}\right)+\int_{0}^{\tilde{\theta}} x\left(p_{B}+\delta \theta\right) d \theta\right] & \text { if } p_{A} \geq p_{B}, \\
-C^{\prime}\left(e_{B}\right)(1+\tilde{\theta}) x\left(p_{B}\right) & \text { if } p_{A}<p_{B} .\end{cases} \\
& \frac{\partial E}{\partial e_{A}}= \begin{cases}(1-\tilde{\theta}) x\left(p_{A}\right) & \text { if } p_{A} \geq p_{B} \\
\int_{\tilde{\theta}}^{0} x\left(p_{A}-\delta \theta\right) d \theta+x\left(p_{A}\right) & \text { if } p_{A}<p_{B}\end{cases} \\
& \frac{\partial E}{\partial e_{B}}= \begin{cases}\int_{0}^{\tilde{\theta}} x\left(p_{B}+\delta \theta\right) d \theta+x\left(p_{B}\right) & \text { if } p_{A} \geq p_{B} \\
(1+\tilde{\theta}) x\left(p_{B}\right) & \text { if } p_{A}<p_{B}\end{cases}
\end{aligned}
$$
if $p_{A}<p_{B}$. if $p_{A} \geq p_{B}$, 
where, in the derivations of Equations A4-A7, we have utilized the following expressions:

$$
\begin{aligned}
\frac{\partial}{\partial p_{A}} \int_{\tilde{\theta}}^{0} x\left(p_{A}-\delta \theta\right) d \theta & =\int_{\tilde{\theta}}^{0} x^{\prime}\left(p_{A}-\delta \theta\right) d \theta-x\left(p_{A}-\delta \tilde{\theta}\right) \frac{\partial \tilde{\theta}}{\partial p_{A}} \\
& =-\frac{1}{\delta}\left[x\left(p_{A}-\delta \theta\right)\right]_{\theta=\tilde{\theta}}^{\theta=0}-\frac{1}{\delta} x\left(p_{A}-\delta \tilde{\theta}\right)=-\frac{1}{\delta} x\left(p_{A}\right), \\
\frac{\partial}{\partial p_{B}} \int_{0}^{\tilde{\theta}} x\left(p_{B}+\delta \theta\right) d \theta & =\int_{0}^{\tilde{\theta}} x^{\prime}\left(p_{B}+\delta \theta\right) d \theta-x\left(p_{B}+\delta \tilde{\theta}\right) \frac{\partial \tilde{\theta}}{\partial p_{B}} \\
& =\frac{1}{\delta}\left[x\left(p_{B}+\delta \theta\right)\right]_{\theta=0}^{\theta=\tilde{\theta}}-\frac{1}{\delta} x\left(p_{B}+\delta \tilde{\theta}\right)=-\frac{1}{\delta} x\left(p_{B}\right) .
\end{aligned}
$$

Evaluating expressions $\mathrm{A} 4-\mathrm{A} 11$ at $p_{A}=p_{B}$ and simplifying, we get an identical expression for the left- and the right-hand derivatives of each of the functions $G_{A}(),. G_{B}($. and $E($.$) . They are all continuous and given by, for i=A, B,{ }^{32}$ One can easily show that the same properties hold for all other partial derivatives of $G_{A}(),. G_{B}($.$) and E($.$) .$

$$
\begin{aligned}
\frac{\partial G_{i}}{\partial p_{i}} & =x\left(p_{i}\right)-\left[p_{i}-C\left(e_{i}\right)\right]\left[\frac{x\left(p_{i}\right)}{\delta}-x^{\prime}\left(p_{i}\right)\right] \\
\frac{\partial E}{\partial p_{i}} & =e_{i} x^{\prime}\left(p_{i}\right) \\
\frac{\partial G_{i}}{\partial e_{i}} & =-C^{\prime}\left(e_{i}\right) x\left(p_{i}\right) \\
\frac{\partial E}{\partial e_{i}} & =x\left(p_{i}\right) .
\end{aligned}
$$

Proof of Lemma 2: Part (i): Consider the case where $p_{A} \geq p_{B}$. We have $\tilde{\theta} \geq 0$ and

$$
\begin{aligned}
W_{A} & =\int_{0}^{\tilde{\theta}}\left[m+S\left(p_{B}+\delta \theta\right)+\phi\left(G_{A}\right)-\varphi(E)\right] d \theta+\int_{\tilde{\theta}}^{1}\left[m+S\left(p_{A}\right)+\phi\left(G_{A}\right)-\varphi(E)\right] d \theta \\
& =U_{A}-\int_{0}^{\tilde{\theta}} S\left(p_{A}\right) d \theta+\int_{0}^{\tilde{\theta}} S\left(p_{B}+\delta \theta\right) d \theta . \\
W_{B} & =\int_{-1}^{0}\left[m+S\left(p_{B}\right)+\phi\left(G_{B}\right)-\varphi(E)\right] d \theta, \\
& =U_{B},
\end{aligned}
$$

where we have made use of the definition of $U_{i}(i=A, B)$ in 10 . 
Similarly, using the definition of $U_{i}(i=A, B)$ for the case $p_{A}<p_{B}$, we have

$$
\begin{aligned}
W_{A} & =\int_{0}^{1}\left[m+S\left(p_{A}\right)+\phi\left(G_{A}\right)-\varphi(E)\right] d \theta, \\
& =U_{A} . \\
W_{B} & =\int_{-1}^{\tilde{\theta}}\left[m+S\left(p_{B}\right)+\phi\left(G_{B}\right)-\varphi(E)\right] d \theta+\int_{\tilde{\theta}}^{0}\left[m+S\left(p_{A}-\delta \theta\right)+\phi\left(G_{B}\right)-\varphi(E)\right] d \theta, \\
& =U_{B}-\int_{\tilde{\theta}}^{0} S\left(p_{B}\right) d \theta+\int_{\tilde{\theta}}^{0} S\left(p_{A}-\delta \theta\right) d \theta .
\end{aligned}
$$

Part (ii): Differentiating Equation 11 with respect to $p_{A}$ and Equation 12 with respect to $p_{B}$, and simplifying, yields

$$
\begin{aligned}
& \frac{\partial W_{A}}{\partial p_{A}}= \begin{cases}\frac{\partial U_{A}}{\partial p_{A}}-\tilde{\theta} S^{\prime}\left(p_{A}\right) & \text { if } p_{A} \geq p_{B} \\
\frac{\partial U_{A}}{\partial p_{A}} & \text { if } p_{A}<p_{B}\end{cases} \\
& \frac{\partial W_{B}}{\partial p_{B}}= \begin{cases}\frac{\partial U_{B}}{\partial p_{B}} \\
\frac{\partial U_{B}}{\partial p_{B}}+\tilde{\theta} S^{\prime}\left(p_{B}\right) & \text { if } p_{A} \geq p_{B}\end{cases}
\end{aligned}
$$

The equality of left- and right-hand derivatives result follows immediately from the fact that at $p_{A}=p_{B}, \tilde{\theta}=0 .{ }^{33}$ One can easily show that the same properties hold for all other partial derivatives of $W_{i}(i=A, B)$.

Proof of Proposition 1: The first-order conditions are:

$$
\begin{aligned}
\frac{\partial W_{i}^{S}}{\partial \tau_{i}} & =\frac{\partial W_{i}^{S}}{\partial p_{i}}=-x\left(p_{i}\right)+\left.\phi^{\prime}\left(G_{i}\right) \frac{\partial G_{i}}{\partial p_{i}}\right|_{e_{i}}-\left.\varphi^{\prime}(E) \frac{\partial E}{\partial p_{i}}\right|_{e_{i}}=0 \\
\frac{\partial W_{i}^{S}}{\partial t_{i}} & =\left.\frac{\partial W_{i}^{S}}{\partial p_{i}} \frac{\partial p_{i}}{\partial t_{i}}\right|_{\tau_{i}}+\left.\frac{\partial W_{i}^{S}}{\partial t_{i}}\right|_{p_{i}}=\left.\frac{\partial W_{i}^{S}}{\partial p_{i}} \frac{\partial p_{i}}{\partial t_{i}}\right|_{\tau_{i}}+\left.\phi^{\prime}\left(G_{i}\right) \frac{\partial G_{i}}{\partial t_{i}}\right|_{p_{i}}-\left.\varphi^{\prime}(E) \frac{\partial E}{\partial t_{i}}\right|_{p_{i}}=0 .
\end{aligned}
$$

Simplifying Equations A24-A25, via differentiation of Equations 14-15, we have

$$
\begin{aligned}
& \frac{\partial W_{i}^{S}}{\partial \tau_{i}}=-x\left(p_{i}\right)+\phi^{\prime}\left(G_{i}\right)\left\{x\left(p_{i}\right)+\left[p_{i}-C\left(e_{i}\right)\right] x^{\prime}\left(p_{i}\right)\right\}-\varphi^{\prime}(E) 2 e_{i} x^{\prime}\left(p_{i}\right)=0 \\
& \frac{\partial W_{i}^{S}}{\partial t_{i}}=\left.\frac{\partial W_{i}^{S}}{\partial p_{i}} \frac{\partial p_{i}}{\partial t_{i}}\right|_{\tau_{i}}+\phi^{\prime}\left(G_{i}\right)\left[-C^{\prime}\left(e_{i}\right) \frac{\partial e_{i}}{\partial t_{i}} x\left(p_{i}\right)\right]-\varphi^{\prime}(E)\left[2 \frac{\partial e_{i}}{\partial t_{i}} x\left(p_{i}\right)\right]=0 .
\end{aligned}
$$

Further algebraic manipulation of Equation A26-A27 simplifies these equations into:

$$
\begin{aligned}
\frac{\partial W_{i}^{S}}{\partial \tau_{i}} & =x\left(p_{i}\right) \phi^{\prime}\left(G_{i}\right) \varepsilon_{i}\left\{\frac{\phi^{\prime}\left(G_{i}\right)-1}{\phi^{\prime}\left(G_{i}\right) \varepsilon_{i}}-\frac{\tau_{i}}{p_{i}}+\frac{e_{i}}{p_{i}}\left[C^{\prime}\left(e_{i}\right)+\frac{2 \varphi^{\prime}(E)}{\phi^{\prime}\left(G_{i}\right)}\right]\right\}=0, \\
\frac{\partial W_{i}^{S}}{\partial t_{i}} & =\frac{\partial W_{i}^{S}}{\partial \tau_{i}} e_{i}+\frac{\phi^{\prime}\left(G_{i}\right) x\left(p_{i}\right)}{C^{\prime \prime}\left(e_{i}\right)}\left[C^{\prime}\left(e_{i}\right)+\frac{2 \varphi^{\prime}(E)}{\phi^{\prime}\left(G_{i}\right)}\right]=0,
\end{aligned}
$$


where we have substituted $\varepsilon_{i}$ for $-p_{i} x^{\prime}\left(p_{i}\right) / x^{\prime}\left(p_{i}\right)$ and $\tau_{i}$ for $p_{i}-C\left(e_{i}\right)+C^{\prime}\left(e_{i}\right) e_{i}$.

First, to prove Equation 17, set $\partial W_{i}^{S} / \partial \tau_{i}=0$ in Equation A29 and simplify.

Second, to prove Equation 16, set $-C^{\prime}\left(e_{i}\right)=2 \varphi^{\prime}(E) / \phi^{\prime}\left(G_{i}\right)$ in Equation A28 and simplify.

Proof of Proposition 2: Summarize country $i$ 's problem through the Lagrangian

$$
\Delta_{i}=m+h\left(x\left(p_{i}\right)\right)-p_{i} x\left(p_{i}\right)+\phi\left(G_{i}\right)-\varphi(E),
$$

where $E=e_{i} x\left(p_{i}\right)+e_{j} x\left(p_{j}\right)$. Thus the difference with the optimization problem of Proposition 1 is only in the treatment of $E$. The proof will then be identical to the proof of Proposition 1 except that $\varphi^{\prime}(E)$ replaces $2 \varphi^{\prime}(E)$ everywhere.

Proof of Proposition 3: To derive the best-reply functions of each country, differentiate Equations 11-12 with respect to the instrument employed. Thus, let $I_{i}$ stand for $\tau_{i}, t_{i}$ or $e_{i}$. We have:

$$
\begin{aligned}
& \frac{\partial W_{A}}{\partial I_{A}}= \begin{cases}\frac{\partial U_{A}}{\partial I_{A}}+\frac{\partial}{\partial I_{A}}\left[-\tilde{\theta} S\left(p_{A}\right)+\int_{0}^{\tilde{\theta}} S\left(p_{B}+\delta \theta\right) d \theta\right] & \text { if } p_{A} \geq p_{B} \\
\frac{\partial U_{A}}{\partial I_{A}} & \text { if } p_{A}<p_{B} .\end{cases} \\
& \frac{\partial W_{B}}{\partial I_{B}}= \begin{cases}\frac{\partial U_{B}}{\partial I_{B}} & \text { if } p_{A} \geq p_{B} \\
\frac{\partial U_{B}}{\partial I_{B}}+\frac{\partial}{\partial I_{B}}\left[+\tilde{\theta} S\left(p_{B}\right)+\int_{\tilde{\theta}}^{0} S\left(p_{A}-\delta \theta\right) d \theta\right] & \text { if } p_{A}<p_{B} .\end{cases}
\end{aligned}
$$

The first-order conditions are found by setting the above equations equal to zero. Note, however, that in Equations A31-A32, only $\partial U_{i} / \partial I_{i}(i=A, B)$ terms matter. Any additional term will vanish at a symmetric equilibrium.

The first-order conditions for country $A$ are then given by,

$$
\begin{aligned}
\frac{\partial U_{A}}{\partial \tau_{A}} & =\frac{\partial U_{A}}{\partial p_{A}}=-x\left(p_{A}\right)+\phi^{\prime}\left(G_{A}\right) \frac{\partial G_{A}}{\partial p_{A}}-\varphi^{\prime}(E) \frac{\partial E}{\partial p_{A}}=0 \\
\frac{\partial U_{A}}{\partial t_{A}} & =\left.\frac{\partial U_{A}}{\partial p_{A}} \frac{\partial p_{A}}{\partial t_{A}}\right|_{\tau_{A}}+\left.\frac{\partial U_{A}}{\partial t_{A}}\right|_{p_{A}} \\
& =\left.\frac{\partial U_{A}}{\partial p_{A}} \frac{\partial p_{A}}{\partial t_{A}}\right|_{\tau_{A}}+\left.\phi^{\prime}\left(G_{A}\right) \frac{\partial G_{A}}{\partial t_{A}}\right|_{p_{A}}-\left.\varphi^{\prime}(E) \frac{\partial E}{\partial t_{A}}\right|_{p_{A}}=0
\end{aligned}
$$

At $p_{A}=p_{B}, e_{A}=e_{B}$, one can simplify Equations A33-A34 by substituting from Equations A14-A15 in Equation A33 and from Equations A16-A17 in Equation A34. 
Same conditions hold for country $B$ and we have:

$$
\begin{aligned}
\frac{\partial U_{i}}{\partial \tau_{i}} & =x\left(p_{i}\right) \phi^{\prime}\left(G_{i}\right) \varepsilon_{i}\left\{\left[\frac{\phi^{\prime}\left(G_{i}\right)-1}{\phi^{\prime}\left(G_{i}\right) \varepsilon_{i}}-\frac{p_{i}-C\left(e_{i}\right)}{\delta \varepsilon_{i}}-\frac{\tau_{i}}{p_{i}}\right]\right. \\
& \left.+\frac{e_{i}}{p_{i}}\left[C^{\prime}\left(e_{i}\right)+\frac{\varphi^{\prime}(E)}{\phi^{\prime}\left(G_{i}\right)}\right]\right\}=0, \\
\frac{\partial U_{i}}{\partial t_{i}} & =\frac{\partial U_{i}}{\partial \tau_{i}} e_{i}+\frac{\phi^{\prime}\left(G_{i}\right) x\left(p_{i}\right)}{C^{\prime \prime}\left(e_{i}\right)}\left[C^{\prime}\left(e_{i}\right)+\frac{\varphi^{\prime}(E)}{\phi^{\prime}\left(G_{i}\right)}\right]=0 .
\end{aligned}
$$

Substituting $\partial U_{i} / \partial \tau_{i}=0$ from Equation A35 into Equation A36 gives us Equation 22 . Setting $-C^{\prime}\left(e_{i}\right)=\varphi^{\prime}(E) / \phi^{\prime}\left(G_{i}\right)$ in Equation A35 then yields Equation 21.

Open economy equilibrium and the variation in $\delta$ : Substitute the optimal value of $\tau_{i}$ from Equation 21 in Equation 5. This yields

$$
p-\frac{p\left[\delta\left(\phi^{\prime}-1\right)-\phi^{\prime} t e\right]}{\phi^{\prime}(p+\delta \varepsilon)}=C(e)+t e,
$$

where we have dropped the subscript $i$ for simplicity in exposition. Differentiate Equations 4, 14, 15, 22 and Equation A37 totally with respect to $\delta .{ }^{34}$ Details of the derivations can be obtained from the authors on request. We have

$$
\begin{aligned}
\frac{d e}{d \delta} & =\frac{-1}{C^{\prime \prime}(e)} \frac{d t}{d \delta} \\
\frac{d E}{d \delta} & =\frac{\phi^{\prime}}{\varphi^{\prime \prime}(E)} \frac{d t}{d \delta} \\
\frac{d p}{d \delta} & =-\frac{p}{e \varepsilon}\left[\frac{\phi^{\prime}}{2 x(p) \varphi^{\prime \prime}(E)}+\frac{1}{C^{\prime \prime}(e)}\right] \frac{d t}{d \delta}
\end{aligned}
$$

with

$$
\frac{d t}{d \delta}=\frac{-\frac{p\left(\phi^{\prime}-1\right)+e \varepsilon \varphi^{\prime}(E)}{\phi^{\prime}(p+\delta \varepsilon)}}{\left[\frac{p}{e \varepsilon}+\frac{\delta(C(e)+t e)}{p e}\right]\left[\frac{\phi^{\prime}}{2 x(p) \varphi^{\prime \prime}(E)}+\frac{1}{C^{\prime \prime}(e)}\right]+\frac{t}{C^{\prime \prime}(e)}+\frac{e \delta \varepsilon}{p}}<0 .
$$

It then follows from Equation A38-A40 that $d e / d \delta>0, d E / d \delta<0$, and $d p / d \delta>0$. Moreover, differentiating $p=C(e)-C^{\prime}(e) e+\tau$ yields

$$
\frac{d \tau}{d \delta}=\frac{d p}{d \delta}+C^{\prime \prime}(e) e \frac{d e}{d \delta}>0 .
$$

Finally, from differentiation of $W^{S}$ as given by Equation 13, we have ${ }^{35}$ If $\varphi^{\prime \prime}(E)=0, e$ does not vary with $\delta$. The signs of the other derivatives remain the same.

$$
\frac{d W^{S}}{d \delta}=-\left[\left(\frac{\phi^{\prime}}{2 \varphi^{\prime \prime}(E)}+\frac{x(p)}{C^{\prime \prime}(e)}\right)\left(\frac{p-C(e)}{\delta \varepsilon}\right)+\frac{\phi^{\prime 2} t}{2 \varphi^{\prime \prime}(E)}\right] \frac{d t}{d \delta}>0 .
$$


Derivation of Equation 24: Differentiate Equation 23 with respect to $\hat{\tau}$, evaluate the resulting expression at $\left(t^{N}, \tau^{N}\right)$ and simplify. We get

$$
\left(\frac{\tau}{p^{2}}-\frac{1}{\delta \varepsilon}\right) \frac{d p}{d \hat{\tau}}+\left\{\frac{C^{\prime}(e)}{\delta \varepsilon}+C^{\prime \prime}(e)\left[\frac{e}{p}+\frac{1}{C^{\prime \prime}(e) e \varepsilon}\right]\right\} \frac{d e}{d \hat{\tau}}=\frac{1}{p} .
$$

Next, from differentiating $p=C(e)-C^{\prime}(e) e+\tau$, we have

$$
\frac{d p}{d \hat{\tau}}=-C^{\prime \prime}(e) e \frac{d e}{d \hat{\tau}}+1
$$

Substituting from A45 into A44 and simplifying yields

$$
\frac{d e^{N}(\hat{\tau})}{d \hat{\tau}}=\frac{1}{C^{\prime \prime}(e) e+\left[\frac{C^{\prime}(e)}{\delta \varepsilon}+\frac{1}{e \varepsilon}\right] /\left[\frac{1}{\delta \varepsilon}+\frac{1}{p}-\frac{\tau}{p^{2}}\right]} .
$$

Equation Equation 24 follows immediately from Equation A46.

Derivation of $\partial W^{S}\left(\tau^{N}, t^{N}\right) / \partial \tau$ and $\partial W^{S}\left(\tau^{N}, t^{N}\right) / \partial t$ : Compare Equations A28-A29 with Equations A35-A36. This reveals that

$$
\begin{aligned}
\frac{\partial W_{i}^{S}}{\partial \tau_{i}} & =\frac{\partial U_{i}}{\partial \tau_{i}}+x\left(p_{i}\right) \phi^{\prime}\left(G_{i}\right) \varepsilon_{i}\left[\frac{p_{i}-C\left(e_{i}\right)}{\delta \varepsilon_{i}}+\frac{e_{i}}{p_{i}} \frac{\varphi^{\prime}(E)}{\phi^{\prime}\left(G_{i}\right)}\right] \\
\frac{\partial W_{i}^{S}}{\partial t_{i}} & =\frac{\partial U_{i}}{\partial t_{i}}+e_{i} x\left(p_{i}\right) \phi^{\prime}\left(G_{i}\right) \varepsilon_{i}\left[\frac{p_{i}-C\left(e_{i}\right)}{\delta \varepsilon_{i}}+\frac{e_{i}}{p_{i}} \frac{\varphi^{\prime}(E)}{\phi^{\prime}\left(G_{i}\right)}\right]+\frac{x\left(p_{i}\right) \varphi^{\prime}(E)}{C^{\prime \prime}\left(e_{i}\right)}
\end{aligned}
$$

where at $\left(\tau^{N}, t^{N}\right), \partial U_{i} / \partial \tau_{i}=\partial U_{i} / \partial t_{i}=0$.

Derivation of 30: Differentiate Equation 29 with respect to $\hat{t}$, evaluate the resulting expression at $\left(t^{N}, \tau^{N}\right)$ and simplify. We get

$$
\frac{\tau}{p^{2}} \frac{d p}{d \hat{t}}-\left(\frac{1}{p}+\frac{1}{\delta \varepsilon}\right) \frac{d \tau}{d \hat{t}}=\frac{e}{p}+\frac{1}{\delta \varepsilon}\left[e+\frac{C^{\prime}(e)}{C^{\prime \prime}(e)}\right] .
$$

Substituting $e+d \tau / d t$ for $d p / d t$ in above and simplifying yields Equation 30 . 


\section{References}

Antweiler, W., Copeland, B.R. and M.S. Taylor (2001) "Is free trade good for the environment?," American Economic Review, 91, 877-908.

Barrett, S. (1994) "Strategic environmental policy and international trade," Journal of Public Economics, 54, 325-338.

Caplan, A.J. and E.C.D. Silva (1999) "Federal acid rain games," Journal of Urban Economics, 46, 25-52.

Chichilinisky, G. (1994) "North-south trade and the global environment," American Economic Review, 84, 851-874.

Conrad, K. (1993) "Taxes and subsidies for pollution-intensive industries as trade policy," Journal of Environmental Economics and Management, 25, 121-135.

Copeland, B.R. and M.S. Taylor (1995) "Trade and transboundary pollution," American Economic Review, 85, 716-737.

Cornes, R. and T. Sandler (1996) The theory of externalities, public goods, and club goods, 2nd edition. Cambridge; New York: Cambridge University Press.

Cremer, H. and F. Gahvari (2000) "Tax evasion, fiscal competition and economic integration," European Economic Review, 44, 1633-1657.

Cremer, H., and F. Gahvari (2001) "Second-best taxation of emissions and polluting goods," Journal of Public Economics, 80, 169-197. 
Cremer, H. and F. Gahvari (2003) "Environmental taxation, tax competition and harmonization," mimeo.

Cremer, H., V. Fourgeaud, M. Leite Monteiro, M. Marchand and P. Pestieau (1996) "Mobility and redistribution: A survey of the literature," Public Finance, 51, 325-352.

Cremer, H. and P. Pestieau (2002) "Mobility and redistribution: A survey," mimeo, University of Toulouse.

Fullerton, D. (1991) "Reconciling recent estimates of the marginal welfare cost of taxation," American Economic Review, 81, 302-308.

Haufler, A. (2001) Taxation in a Global Economy. Cambridge: Cambridge University Press.

Kanbur, R. and M. Keen (1993) "Jeux sans frontières: Tax competition and tax coordination when countries differ in size," American Economic Review, 83, 877-892.

Kanbur, R., Keen, M. and S. van Wijnbergen (1995) "Industrial competitiveness, environmental regulation and direct foreign investment," in The Economics of Sustainable Development, ed. Goldin I. and L.A. Winters. Cambridge; New York and Melbourne: Cambridge University Press, 289-302.

Karp, L., Sacheti, S. and J. Zhao (2001) "Common ground between free-traders and environmentalists," International Economic Review, 42, 617-647. 
Keen, M.J. (1989) "Pareto-improving indirect tax harmonisation," European Economic Review, 33, 1-12.

Kennedy, P.W. (1994) "Equilibrium pollution taxes in open economies with imperfect competition," Journal of Environmental Economics and Management, 27, 49-63.

Lockwood, B. (2001) "Tax competition and tax co-ordination under destination and original principles: a synthesis," Journal of Public Economics, 81, 279-319.

Mintz, J. and H. Tulkens (1986) "Commodity tax competition between member states of a federation: equilibrium and efficiency," Journal of Public Economics, 29, 133-172.

Oates, W.E. (2001) "A reconsideration of environmental federalism," Resources for the Future, Discussion Paper 01-54.

Silva, E.C.D. and A.J. Caplan (1997) "Transboundary pollution control in federal systems," Journal of Environmental Economics and Management, 34, 173-186.

Ulph, A. (1997) "International trade and the environment: A survey of recent economic analysis," in The International Yearbook of Environmental and Resource Economics 1997/8, ed. Folmer, H. and T. Tietenberg, Eds.. Gloucester, England: Edward Elgar, 205-242.

Ulph, A. (2000) "Harmonization and optimal environmental policy in a federal system with asymmetric information," Journal of Environmental Economics and Management, 39, 224-241. 
Wellisch, D. (2000) Theory of Public Finance in a Federal State. Cambridge: Cambridge University Press.

Wilson, J. (1999) "Theories of tax competition," National Tax Journal, 52, 269-304. 


\section{Footnotes}

1. As measured for instance by the negative of the stock of $\mathrm{CO}_{2}$ in the atmosphere.

2. There is a vast literature on the inefficiency of non-cooperative provision of public goods; see, e.g., Cornes and Sandler (1996). In the context of transboundary emission, see Silva and Caplan (1997), and Caplan and Silva (1999). They examine the roles of federal and regional governments in combating pollution abstracting from tax competition.

3. The tax competition have recently been surveyed by Cremer et al. (1996), Wilson (1999), Wellisch (2000) and Haufler (2001). For specific applications to environmental issues, see Oates (2001).

4. There are papers which contain both strategic trade consideration and transboundary pollution; see, e.g., Conrad (1993) and Kennedy (1994). However, these papers are partial equilibrium in nature and model imperfectly competitive environments. As such, they do not explore the full interactions between tax competition and transboundary pollution.

5. The targeting issue has been noted in the literature; see, e.g., Barrett (1994). Again, this has been studied within a partial equilibrium framework with restricted instruments.

6. Harmonization of a single instrument has been discussed in the literature. See Kanbur et al. (1995) and Ulph (2000) in the context of environmental policies and Keen (1989) and Kanbur and Keen (1993) for a general discussion. "Partial harmonization", as far as we know, was first discussed by Cremer and Gahvari (2000) in the context of tax evasion. See also the survey by Cremer and Pestieau (2002).

7. There are numerous other trade models. Copeland and Taylor (1995), for example, motivate trade through income differences and show that trade worsens the environment by making rich countries specialize in production of clean goods and poor countries (with less stringent regulations) in dirty goods. They generalize 
their setup in Antweiler et al. (2001) by including factor abundance in determining trade. There are also papers that study the impact of trade on environmental resources; see, e.g., Chichilinisky (1994) and Karp et al. (2001) who build models of North-South trade and motivate trade through differences in property rights.

8. Firms also choose the environmental technologies with a view to maximize profits. This treatment differs from that of the literature on strategic environmental policies and trade with imperfect competition where the technology choices (e.g. through $\mathrm{R} \& \mathrm{D})$ are made strategically by firms. The latter approach adds additional features which are not treated here because of the competitive assumptions.

9. See Cremer and Gahvari (2001) for a thorough discussion of the properties of output taxes versus emission taxes in the context of a closed economy.

10. This models situations where a polluting good may be produced through different production techniques, or using different polluting inputs where each particular input entails a different emission level. Different abatement techniques also imply that a unit of polluting good is associated with different emission levels.

11. More precisely the assumption is that $C^{\prime}()<$.0 for all $e_{i}(i=A, B)$ up to some limit $\bar{e}$, and that $C^{\prime}(\bar{e})=0$.

12. All taxes are origin-based.

13. If $\delta=0$, individuals become identical in all respects. Under this circumstance, any deviation in price implies that no one will purchase from the state which has a higher price. Observe also that our approach is similar in structure to a model with cross-border shopping; see, e.g., Kanbur and Keen (1993). The disutility from consumption of foreign-produced goods here plays the same role as transportation cost, with different individuals facing different transportation costs reflecting their distance from the "border".

14. We rule out lump-sum taxes. This is in line with the literature on tax competition. However, unlike that literature, allowing for lump-sum taxation here does not 
make tax competition disappear. This special case is studied in Cremer and Gahvari (2003). In the context of our model, ruling out lump-sum taxes implies ruling out taxation of the numeraire good. Alternatively, we can allow for a tax on $m$ provided that its value is fixed.

15. If $m$ is taxed at some fixed rate $\bar{m}$, one must add this to the right-hand side formulas. It is plain that this will have no impact on our formulation as long as the desired expenditure levels on $G$ exceed $\bar{m}$.

16. These are the people with a $\theta \in[0, \tilde{\theta})$ for whom the net cost of buying one unit of the good from $B$ is $p_{B}+\delta \theta<p_{A}$.

17. Despite the "full cooperation" between the countries, the absence of lump-sum taxes implies that the optimal benchmark is second best.

18. If individuals have no preference for home-produced goods, i.e. if $\delta=0$, each state will be able to take over the production of $x$ in its entirety by selling at a price just below the other state's price. Under this circumstance, the price is pushed all the way down to the marginal cost so that $p_{i}-C\left(e_{i}\right)=\tau_{i}-C^{\prime}\left(e_{i}\right) e_{i}=0$. Consequently, in the absence of other taxes, $G_{i}=0$. Observe also that by substituting for $G_{i}$ from 14 in 21 , one can rewrite it as

$$
\frac{\tau_{i}}{p_{i}}=\frac{\phi^{\prime}\left(G_{i}\right)-1}{\phi^{\prime}\left(G_{i}\right) \varepsilon_{i}}-\frac{p_{i}-C\left(e_{i}\right)}{\delta \varepsilon_{i}} .
$$

Next, substituting for $\tau_{i}$ from this equation and for $t_{i}$ from 22 in $p_{i}=C\left(e_{i}\right)+$ $t_{i} e_{i}+\tau_{i}$ yields, after a bit of algebraic manipulation,

$$
p_{i}-C\left(e_{i}\right)=\frac{\delta}{p_{i}+\delta \varepsilon_{i}} \frac{\varphi^{\prime}(E) e_{i} \varepsilon_{i}+p_{i}\left[\phi^{\prime}\left(G_{i}\right)-1\right]}{\phi^{\prime}\left(G_{i}\right)} .
$$

It follows from this equation that as $\delta \rightarrow 0, p_{i} \rightarrow C\left(e_{i}\right)$.

19. See, among others, Mintz and Tulkens (1986). Lockwood (2001) has termed these externalities "consumer price spillovers".

20. Observe that the global nature of emissions here introduces a third source of externality: The increase in the home-country's tax increases the price of the 
polluting good and reduces its consumption. Consequently, aggregate emissions fall, benefiting the foreign country residents as well. However, this is not a fiscal externality and is also present when the economy is closed.

21. The assumption of a constant $\phi^{\prime}(G)$ is not unreasonable, if one remembers that variations in emission taxes are unlikely to change the MCPF by much (although such variations will change the environmental tax revenues).

22. This will be the case if $e_{i} \varphi^{\prime}(E)>\delta\left(1-1 / \phi^{\prime}\right)$. The latter condition will be satisfied if $\phi^{\prime}$ is "close" to one, i.e. if MCPF is "low", or if $\delta$ is "low".

23. If $\varphi^{\prime \prime}(E)=0, e_{i}$ remains unaffected.

24. We have carried out numerous simulations assuming $\phi^{\prime}\left(G_{i}\right)$ is not constant. In all cases we find similar results. The only exception is that it is possible for the emission tax to decline so that technologies become more polluting. Indeed, one can show that when demand is perfectly inelastic, $t_{i}$ must decline and $e_{i}$ must increase. Nevertheless aggregate emissions always increase and overall welfare declines.

25. The best-reply function for $i$ is given by equation A34 in the Appendix when $\tau_{i}$ is set at $\hat{\tau}$.

26. That is, the solution to 23 in conjunction with equations $2,4,5,14$, and 18 . If $\delta=0$, tax competition pushes the price down to the point such that $p_{i}-C\left(e_{i}\right)=$ $\hat{\tau}-C^{\prime}\left(e_{i}\right) e_{i}=0$. Consequently, $e_{i}$ is determined according to $C^{\prime}\left(e_{i}\right) e_{i}=\hat{\tau}$. Observe that if $\hat{\tau}>0, e_{i}>\bar{e}$.

27. A sufficient condition is that $\delta>-C^{\prime}(e) e$.

28. This may appear counterintuitive as one expects the two countries to have an incentive to unilaterally lower their emission tax rate if they cannot compete in $\tau$. However, this does not necessarily imply that the constrained Nash-equilibrium level of $t$ decreases. That depends on where the two countries' new best-reply 
functions (in emission taxes) intersect. We have numerical examples for both possibilities.

29. Recall that under either of these assumptions, the unrestricted Nash equilibrium value of $\tau$ is negative. Specifically, from 21$), T^{N}<0$, if $p-C(e)>\delta\left[1-1 / \phi^{\prime}(G)\right]$.

30. Of course, one must solve 29 in conjunction with equations $(2,4,5,14$, and 18). Note also that the best-reply function for $i$ is given by equation A35 in the Appendix when $t_{i}$ is set at $\hat{t}$. If $\delta=0$, tax competition pushes the price down to the point where $p_{i}-C(\hat{e})=\tau+\hat{t} \hat{e}=0$. Consequently, $\tau=-\hat{t} \hat{e}$.

31. We have again dropped the $i$ subscript for ease in notation.

32. One can easily show that the same properties hold for all other partial derivatives of $G_{A}(),. G_{B}($.$) and E($.$) .$

33. One can easily show that the same properties hold for all other partial derivatives of $W_{i}(i=A, B)$.

34. Details of the derivations can be obtained from the authors on request.

35. If $\varphi^{\prime \prime}(E)=0, e$ does not vary with $\delta$. The signs of the other derivatives remain the same. 